\title{
Isobaric Study of the Elastic Properties for Alkaline Earth Oxides under High Temperature
}

\author{
Seema Gupta, ${ }^{1,2}$ S. P. Singh, ${ }^{2}$ and S. C. Goyal ${ }^{1,2,3}$ \\ ${ }^{1}$ Department of Physics, Agra College, Agra 282002, India \\ ${ }^{2}$ Department of Physics, Goverment Degree College, Sambhal, Moradabad, India \\ ${ }^{3}$ K. P. Engineering College, N. H. 2, Etmadpur, Agra 283202, India \\ Correspondence should be addressed to Seema Gupta, seema_g_khushi@yahoo.co.in \\ Received 20 September 2010; Revised 7 March 2011; Accepted 9 March 2011 \\ Academic Editor: Fahrettin Yakuphanoglu
}

Copyright (c) 2011 Seema Gupta et al. This is an open access article distributed under the Creative Commons Attribution License, which permits unrestricted use, distribution, and reproduction in any medium, provided the original work is properly cited.

\begin{abstract}
A simple and straightforward theoretical model is developed to investigate the elastic properties of alkaline earth oxides under the effect of temperature as well as pressure. The calculation is performed with the help of high pressure-high temperature equation of state based on thermodynamic analysis. The anharmonic term arising due to thermal expansion has been taken into account in the expansion of logarithmic series of the thermodynamic data. The results obtained for alkaline earth oxides are discussed and compared with experimental data under the combined effect of high temperature and high pressure. The results are found to be in good agreement with available experimental results.
\end{abstract}

\section{Introduction}

The equation of state (EOS) gives us valuable information about the change in bulk under the influence of temperature at a fixed pressure and is thus related to the compression of solids. The study of elasticity plays an important role in describing the high-temperature behaviour of solids. The studies based on the equation of state (EOS) are vide importance in physics as well as in chemistry and in the earth sciences $[1,2]$. The theoretical studies of EOS at high temperature and pressure are of fundamental interest because they permit interpolation and extrapolation into the regions in which the experimental data are spares or lacking.

It is the necessary to know the effects of the temperature and pressure on the elastic properties of alkaline earth oxides (AEOs) throughout the upper mantle of the Earth for better understanding about its structure, compositions, and mineralogy. The properties of alkaline earth oxides solids under varying conditions of temperature and pressure have attracted the attention of theoretical and experimental workers [3-9] because of their need in different branches of science [10].
The problem of evaluation of elastic moduli can be tackled in two different ways, for example, (i) by determining the constants or elastic moduli from temperature relationship, termed as equation of state [3-7] and (ii) by choosing suitable interionic potential and there by evaluating elastic constants and elastic moduli [11-13]. Both methods help us to determine various properties of solids under varying conditions of pressure and temperature. It has been observed that the methods based on the theory of interionic potentials are very tedious [11-16] and involve a lot of computational work in addition to various approximation and it fails to evaluate the elastic constants or elastic moduli of complicated solids.

The purpose of the present study is to present a simple and straightforward method for evaluation of elastic constants of simple and complex solids at different temperatures. To determine the temperature dependence of elastic constants and their combination, different relations based on thermodynamic parameters have been proposed in the literature [17]. The well-known and widely used relations for predicting the temperature dependence of elastic constants are discussed by Suzuki et al. [18] and by 


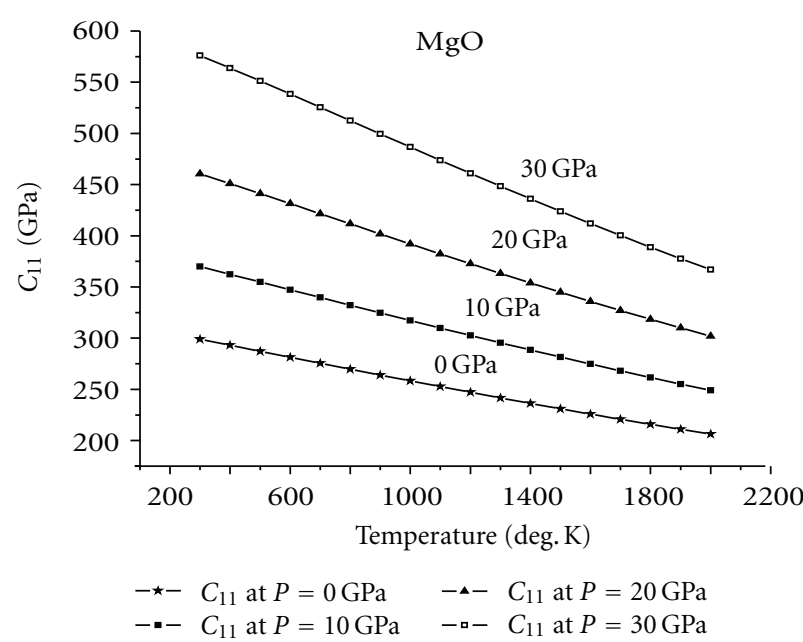

(a)

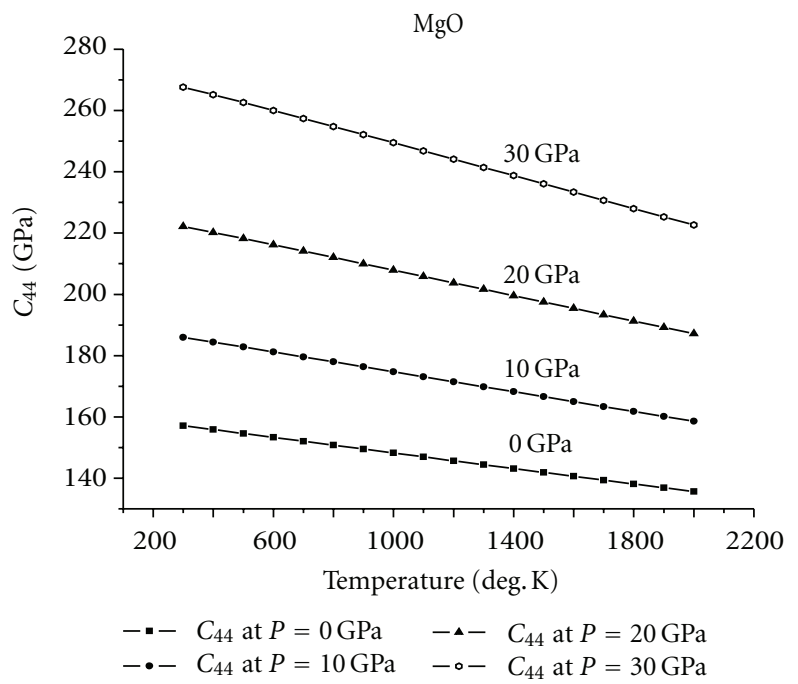

(c)

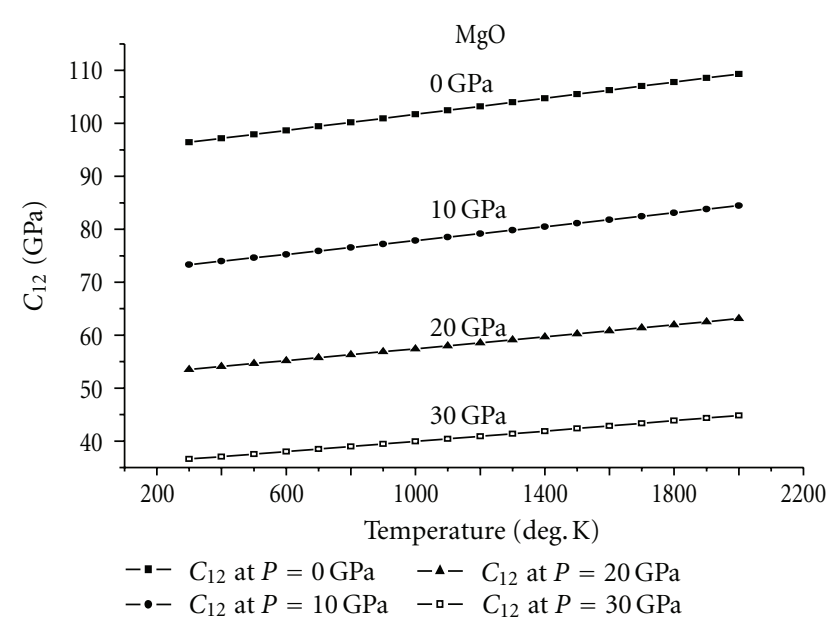

(b)

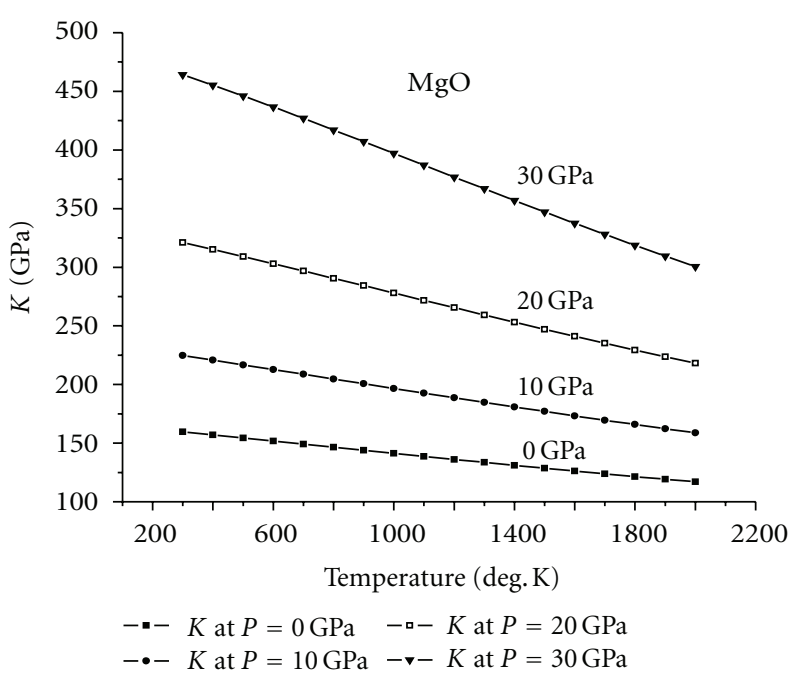

(d)

Figure 1: (a) Isobars of $C_{11}$ at different temperatures for $\mathrm{MgO}$, (b) isobars of $C_{12}$ at different temperatures for $\mathrm{MgO},(\mathrm{c})$ isobars of $C_{44}$ at different temperature for $\mathrm{MgO}$, and (d) isobars of $\mathrm{Ks}$ at different temperatures for $\mathrm{MgO}$.

Singh and Kumar [6]. The relation of Suzuki et al. [18] involves the complicated analytical form, and, hence, the complex computational work is required. Moreover, this relation predicts good results for the variation of volume but not for the elastic constants. This relation has further been simplified by Singh and Kumar [6] by considering the volume dependence of Anderson-Gruneisen parameter, though the methodology followed by these workers is too simple to explain the temperature dependence of elastic constants and the results are not good. It may be due to the reason that they have ignored the higher-order terms, that is, anharmonic terms, in the expansion of the logarithmic series of volume change.

In the present study, we have considered the anharmonic terms in the expansion of logarithmic series of volume change with temperature and probably first time investigated the temperature dependence of elastic constants up to $2000 \mathrm{~K}$ of alkaline earth oxides at different pressures up to $100 \mathrm{GPa}$. The results predicted by the developed theory in case of alkaline earth oxides are critically discussed.

\section{Theory}

The theory is based on the sound thermodynamic analysis which includes properly the volume dependence of Anderson-Gruneisen parameter. Following Singh et al. [4], Singh and Kumar [6], Joshi and Gupta [7], and Kumar $[5,20-22]$, the relation for the change in volume to the volume is given by

$$
\frac{V}{V_{0}}-1=-\frac{1}{A} \ln \left[1+\frac{A}{K_{0}}\left\{P-\alpha_{0} \beta_{0}\left(T-T_{0}\right)\right\}\right] .
$$




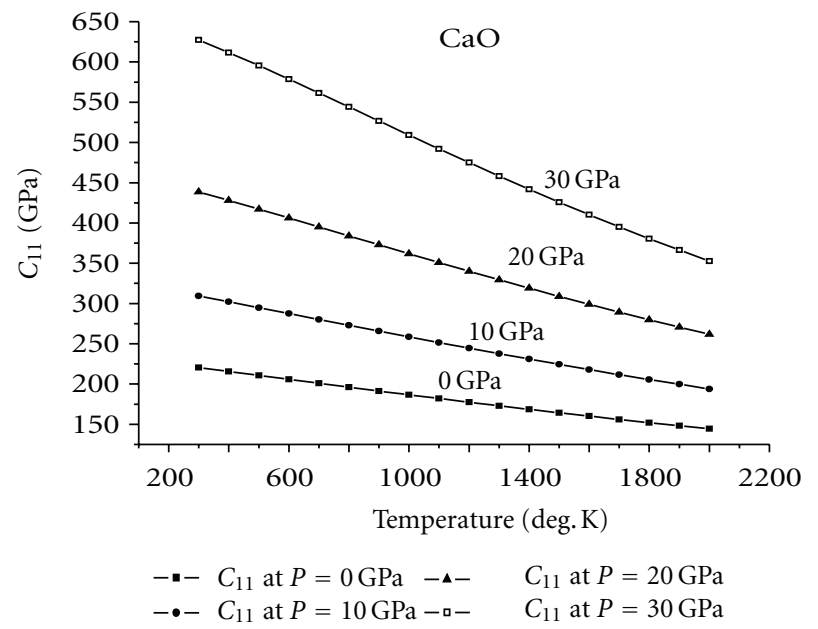

(a)

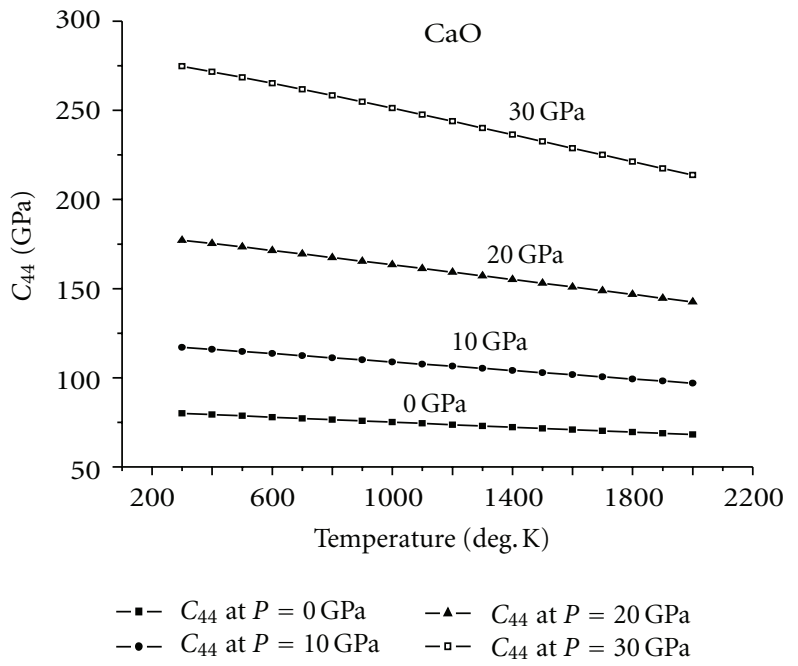

(c)

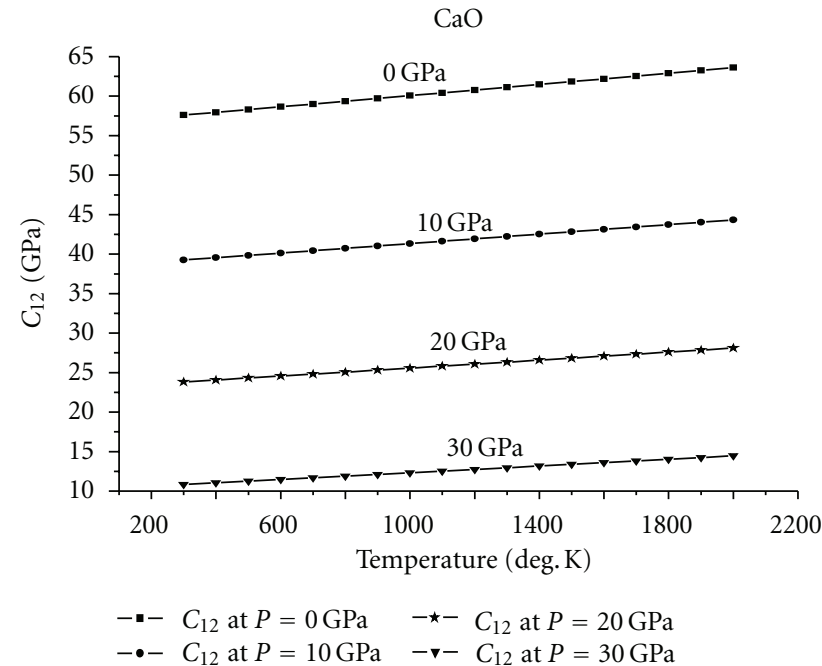

(b)

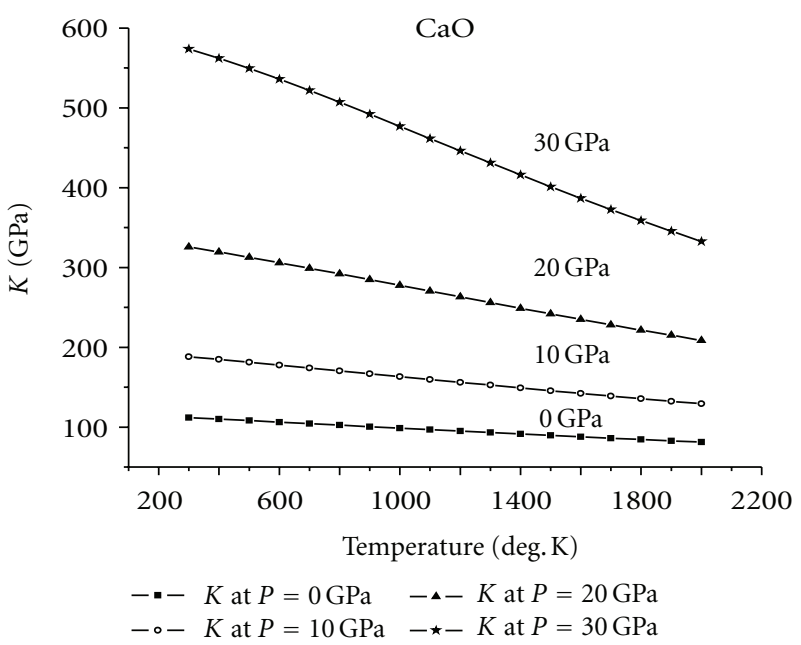

(d)

Figure 2: (a) Isobars of $C_{11}$ at different temperatures for $\mathrm{CaO}$, (b) isobars of $C_{12}$ at different temperatures for $\mathrm{CaO}$, (c) isobars of $C_{44}$ at different temperatures for $\mathrm{CaO}$, and $(\mathrm{d})$ isobars of $\mathrm{K}$ at different temperatures for $\mathrm{CaO}$.

Equation (1) can be written as follows

$$
\frac{V}{V_{0}}-1=-\frac{1}{A} \ln \left[1-\frac{A}{K_{0}}\left\{\alpha_{0} \beta_{0}\left(T-T_{0}\right)-P\right\}\right],
$$

where $A$ is the parameter and is given by $A=\left(\delta^{0}+1\right) \approx$ $\left(K_{0}^{\prime}+1\right)$ as discussed in detail by Badi and Kumar [15], $\alpha_{0}$ is the thermal expansion coefficient at $T_{0}$, and $K_{0}^{\prime}$ is the first-order pressure derivative of bulk modulus, which can be assumed nearly equal to $\delta_{0}$ as mentioned elsewhere [47]. On expanding (2) and considering the terms up to third order, the high-order term, (2) becomes as follows:

$$
\begin{aligned}
\frac{V}{V_{0}}-1=\frac{1}{A}[ & e^{\alpha_{0} A\left(T-T_{0}\right)-A P / K_{0}}-1 \\
& \left.+\frac{\left\{\alpha_{0} A\left(T-T_{0}\right)-P A / K_{0}\right\}^{3}}{6}\right] .
\end{aligned}
$$

Using the definition of the coefficient of volume thermal expansion $\alpha$ as $\alpha=(1 / V)(d V / d T)_{P}$, (3) gives the following relation:

$$
\begin{aligned}
& \frac{\alpha}{\alpha_{0}} \\
& \left.=\frac{e^{\alpha_{0} A\left(T-T_{0}\right)-A P / K_{0}}+\left\{\alpha_{0} A\left(T-T_{0}\right)-A P / K_{0}\right\}^{2} / 2}{1+(1 / A)\left\{e^{\alpha_{0} A\left(T-T_{0}\right)-A P / K_{0}}-1+\left\{\alpha_{0} A\left(T-T_{0}\right)-A P / K_{0}\right\}^{3} / 6\right.}\right\} .
\end{aligned}
$$

Now, if we use the approximation that $(\alpha K)$ is independent of $T$, this gives

$$
\alpha K=\alpha_{0} K_{0} .
$$




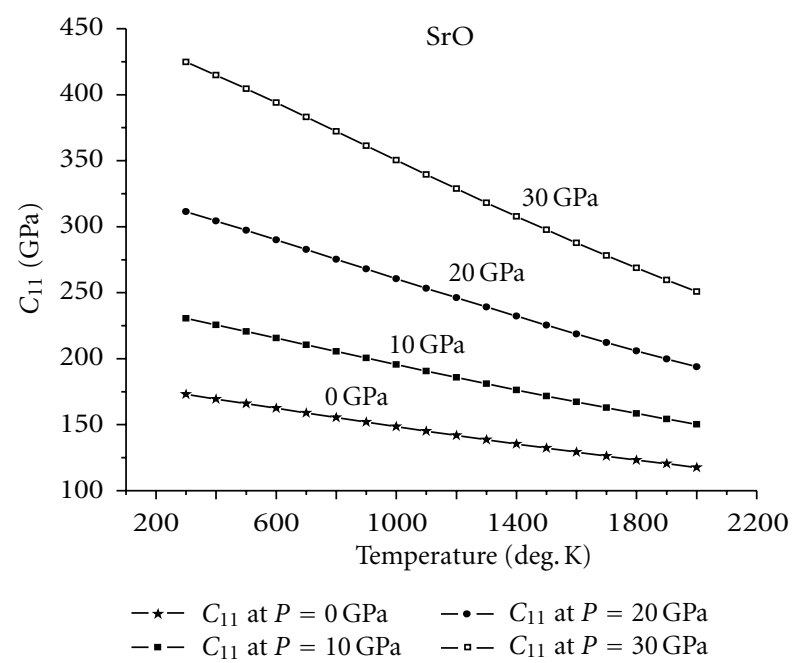

(a)

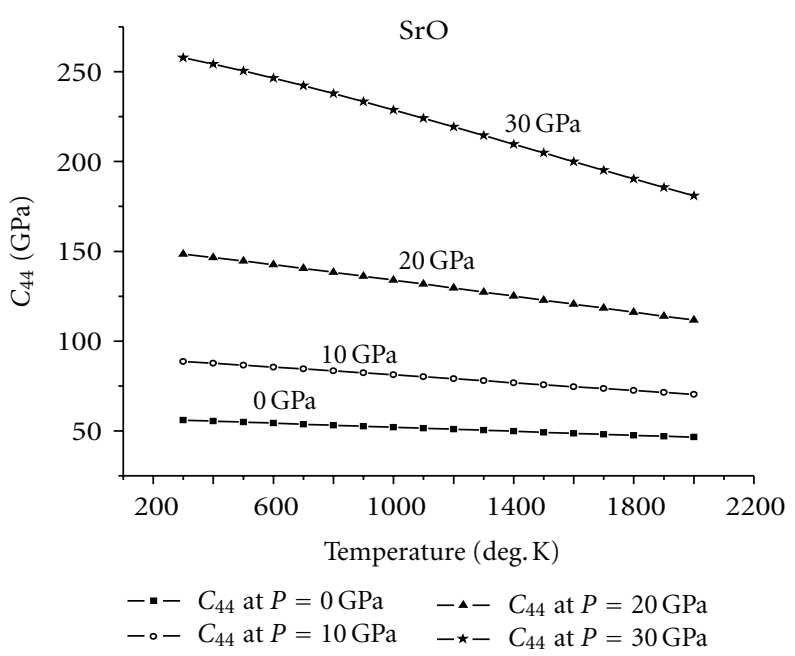

(c)

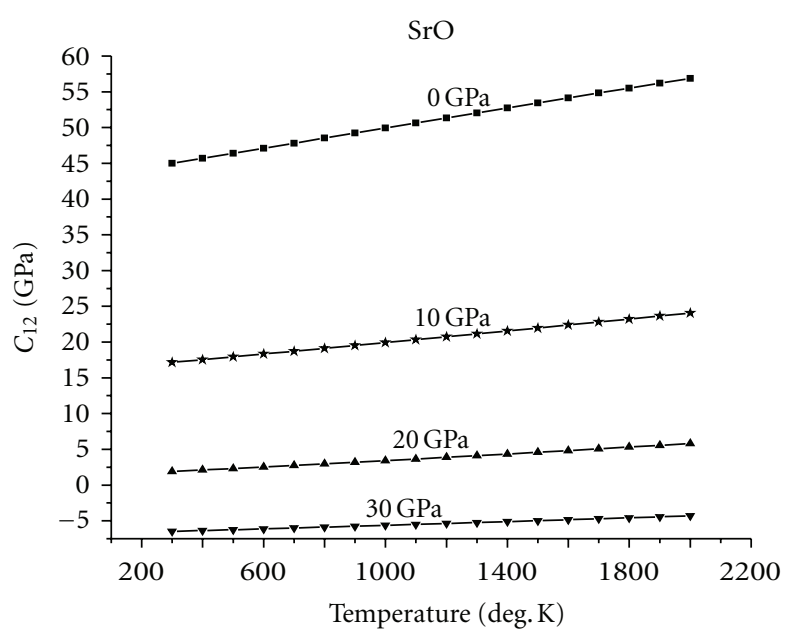

-.- $C_{12}$ at $P=0 \mathrm{GPa} \quad-\Delta-C_{12}$ at $P=20 \mathrm{GPa}$

$-\star-C_{12}$ at $P=10 \mathrm{GPa} \quad-\mathbf{v}-C_{12}$ at $P=30 \mathrm{GPa}$

(b)

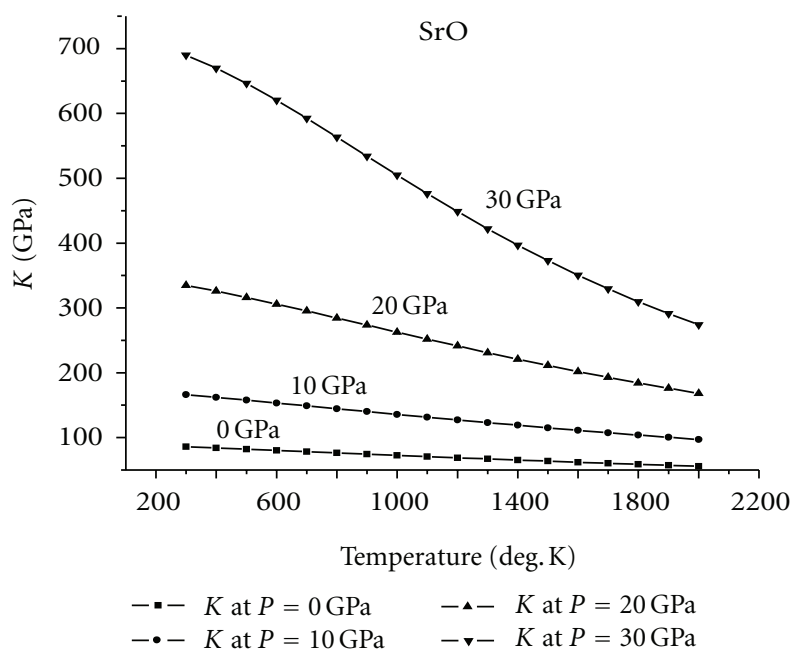

(d)

Figure 3: (a) Isobars of $C_{11}$ at different temperatures for SrO, (b) isobars of $C_{12}$ at different temperatures for SrO, (c) isobars of $C_{44}$ at different temperatures for SrO, and (d) isobars of $K$ at different temperatures for SrO.

Thus, (5) may be rewritten for $B / B_{0}$ as follows:

$$
\begin{aligned}
& \frac{K}{K_{0}} \\
& =\frac{1+(1 / A)\left[e^{\alpha_{0} A\left(T-T_{0}\right)-A P / K_{0}}-1+\left\{\alpha_{0} A\left(T-T_{0}\right)-A P / K_{0}\right\}^{3} / 6\right]}{e^{\alpha_{0} A\left(T-T_{0}\right)-A P / K_{0}}+\left\{\alpha_{0} A\left(T-T_{0}\right)-A P / K_{0}\right\}^{2} / 2} .
\end{aligned}
$$

We can generalize (6) as follows:

$$
\begin{aligned}
& \frac{M}{M_{0}} \\
& =\frac{1+(1 / A)\left[e^{\alpha_{0} A\left(T-T_{0}\right)-A P / K_{0}}-1+\left\{\alpha_{0} A\left(T-T_{0}\right)-A P / K_{0}\right\}^{3} / 6\right]}{e^{\alpha_{0} A\left(T-T_{0}\right)-A P / K_{0}}+\left\{\alpha_{0} A\left(T-T_{0}\right)-A P / K_{0}\right\}^{2} / 2} .
\end{aligned}
$$

From (7), the collective expressions for the temperature dependence of second-order elastic constants may be written as

$$
\frac{C_{i j}}{C_{i j}^{0}}
$$

$$
=\frac{1+(1 / A)\left[e^{\alpha_{0} A\left(T-T_{0}\right)-A P / K_{0}}-1+\left\{\alpha_{0} A\left(T-T_{0}\right)-A P / K_{0}\right\}^{3} / 6\right]}{e^{\alpha_{0} A\left(T-T_{0}\right)-A P / K_{0}}+\left\{\alpha_{0} A\left(T-T_{0}\right)-A P / K_{0}\right\}^{2} / 2} .
$$

\section{Results and Discussion}

The values of temperature dependent of Second order elastic constants the bulk modulus of alkaline oxides at differnt pressure are computed with the help of above described 
TABle 1: Values of input data $[5,6,9,10,13,19]$ at room temperature. $\alpha$ (in $10^{-5} \mathrm{~K}^{-1}$ ), $\delta^{0}$ (dimensionless); elastic constants $\left(C_{i j}\right)$ and bulk modulus $(K)$ (in $\mathrm{GPa}$ ); and first-order temperature derivatives $\left(\left(\partial C_{i j} / \partial T\right)_{0}\right)$ (in $\left.10^{-2} \mathrm{GPa}\right)$.

\begin{tabular}{lccc}
\hline Parameters & $\mathrm{MgO}$ & $\mathrm{CaO}$ & $\mathrm{SrO}$ \\
\hline$\delta^{0}$ & 5.3 & 5.6 & 5.4 \\
$\alpha$ & 3.12 & 3.04 & 4.20 \\
$C_{11}^{0}$ & 298.906 & 220.53 & 173.00 \\
$C_{12}^{0}$ & 96.4 & 57.60 & 45.0 \\
$C_{44}^{0}$ & 157.13 & 80.03 & 56.0 \\
$K$ & 159.67 & 111.96 & 86.0 \\
$\left(\partial C_{11} / \partial T\right)_{0}$ & -5.85 & -4.90 & -3.52 \\
$\left(\partial C_{12} / \partial T\right)_{0}$ & 0.75 & 0.35 & 0.7 \\
$\left(\partial C_{44} / \partial T\right)_{0}$ & -1.26 & -0.70 & -0.56 \\
\hline
\end{tabular}

theory using input data from Table 1. By using (6) and (8), we have thus calculated the values of the temperature dependence of second-order elastic constants and the bulk modulus of alkaline earth oxides at different pressure. The results are plotted in Figures 1, 2, and 3 from $300 \mathrm{~K}$ to $2000 \mathrm{~K}$ at different pressures for $\mathrm{MgO}, \mathrm{CaO}$, and $\mathrm{SrO}$.

It is interesting to note from Figures 1(a), 2(a), and 3(a) that the values of $C_{11}$ and $C_{44}$ are decreasing with increase of temperature at $0 \mathrm{GPa}, 10 \mathrm{GPa}, 20 \mathrm{GPa}$, and $30 \mathrm{GPa}$ isobars in all cases $(\mathrm{MgO}, \mathrm{CaO}$, and $\mathrm{SrO})$. But the values of $C_{12}$ are increasing with increase of temperature at all the pressure range. This clearly shows that there is a softening of the $C_{11}$ and $C_{44}$ elastic constants, while the values of $C_{12}$ are slowly increasing with increase of temperature (Figures $1(\mathrm{~b})$, 2(b), and 3(b)), at $0-30 \mathrm{GPa}$. It is also interesting to note that from Figures $1(\mathrm{c}), 2(\mathrm{c})$, and $3(\mathrm{c})$ the values of $C_{44}$ are decreasing with increase of temperature for 0-30 GPa. This is in good agreement with the experimental values at ambient condition. Thus, the behavior of $C_{11}$ and $C_{44}$ seems to be similar with increase of temperature at different pressure. If we draw our attention on Figures 1(d), 2(d), and 3(d) for the bulk modulus, we get the same pattern as that of $C_{11}$; that is, the values of $K$ are decreasing with increase of temperature at $0 \mathrm{GPa}, 10 \mathrm{GPa}, 20 \mathrm{GPa}$, and $30 \mathrm{GPa}$ isobars in all cases $(\mathrm{MgO}$, $\mathrm{CaO}$, and $\mathrm{SrO})$.

It is interesting to note from Figures 1, 2, and 3 that the softening of the bulk modulus increases with increase of pressure. Thus, the behavior of elastic constants with increase of temperature at low pressure $(0-10 \mathrm{Gpa})$ is different as compared to at high pressure $(20-30 \mathrm{GPa})$. Such analysis regarding the behavior of elastic constants at different temperatures and pressures of alkaline earth oxides may be useful in explaining the physical properties like Debye temperature, elastic wave velocity, and so forth in geophysics.

\section{Acknowledgments}

S. Gupta is grateful to DST for providing the financial Assistance, S. P. Singh is grateful to the Principal, Agra College, Agra for providing the facilities, and one of the authors (S. C. Goyal) is thankful to UGC for proving the financial assistance. The authors are also thankful to the referee for pointing out the errors.

\section{References}

[1] R. M. Hazen and L. W. Finger, Comparative Crystal Chemistry, John Wiley \& Sons, New York, NY, USA, 1982.

[2] R. Chidambaram and S. M. Sharma, "Frontiers in highpressure physics research," Current Science, vol. 60, no. 7, pp. 397-408, 1991.

[3] M. Singh, P. P. Singh, M. Kumar, and B. R. K. Gupta, Indian Journal of Physics, vol. 74A, no. 6, pp. 613-616, 2000.

[4] M. Singh, P. P. Singh, B. R. K. Gupta, and M. Kumar, "Temperature and pressure dependence of elastic constants," High Temperatures-High Pressures, vol. 33, no. 2, pp. 199206, 2001.

[5] M. Kumar, "Application of high pressure-high temperature equation of state for elastic properties of solids," Physica B, vol. 311, no. 3-4, pp. 340-347, 2002.

[6] P. P. Singh and M. Kumar, "Temperature dependence of bulk modulus and second-order elastic constants," Physica B, vol. 344, no. 1-4, pp. 41-51, 2004.

[7] M. Joshi and B. R. K. Gupta, Indian Journal of Physics, vol. 80, no. 1, pp. 85-87, 2007.

[8] O. L. Anderson and D. G. Isaak, "The dependence of the Anderson-Grüneisen parameter $\delta_{\mathrm{T}}$ upon compression at extreme conditions," Journal of Physics and Chemistry of Solids, vol. 54, no. 2, pp. 221-227, 1993.

[9] D. G. Isaak, "High-temperature elasticity of iron-bearing olivines," Journal of Geophysical Research, vol. 97, no. 2, pp. 1871-1885, 1992.

[10] O. L. Anderson and D. G. Isaak, Mineral Physics and Crystallography: A Hand Book of Physical Constants, vol. 2, American Geophysical Union, UCLA Press, Los Angeles, Calif, USA, 1995.

[11] S. P. Singh, S. Gupta, and S. C. Goyal, "Elastic properties of alkaline earth oxides under high pressure," Physica B, vol. 391, no. 2, pp. 307-311, 2007.

[12] T. H. Kwon and S. C. Kim, "Thermal properties of NaCl crystal under high pressure," Physica B, vol. 205, no. 3-4, pp. 331-334, 1995.

[13] S. S. Bedi and M. S. Bhangoo, "Temperature and pressure dependence of elastic properties of earth's lower mantle components," Modern Physics Letters B, vol. 10, no. 15, pp. 697-703, 1996.

[14] S. S. Badi and M. S. Bhangoo, "Advanced in high pressure res," in Condensed Matter, pp. 526-531, NISCOM, New Delhi, India, 1997.

[15] S. S. Badi and M. Kumar, "Temperature dependence of elastic constants: $\mathrm{MgO}$ as an example," High Temperatures-High Pressures, vol. 27-28, pp. 595-598, 1995-1996.

[16] R. K. Singh, S. S. Mitra, and C. N. Rao, "Temperature variations of the elastic constants of CaF2 and SrF2 crystals," Physical Review B, vol. 44, no. 2, pp. 838-840, 1991.

[17] O. L. Anderson, Equation of State of Solids for Geophysics and Ceramic Science, Oxford University Press, Oxford, UK, 1995.

[18] I. Suzuki, S. I. Okajima, and K. Seya, "Thermal expansion of single-crystal manganosite," Journal of Physics of the Earth, vol. 27, no. 1, pp. 63-69, 1979.

[19] P. R. Son and R. A. Bartels, " $\mathrm{CaO}$ and SrO single crystal elastic constants and their pressure derivatives," Journal of Physics and Chemistry of Solids, vol. 33, no. 4, pp. 819-828, 1972. 
[20] M. Kumar, "High pressure equation of state for solids," Physica $B$, vol. 212, no. 4, pp. 391-394, 1995.

[21] M. Kumar, "Application of high pressure equation of state for different classes of solids," Physica B, vol. 217, no. 1-2, pp. 143148, 1996.

[22] M. Kumar, "Author's reply on the remark of Prieto and Renero on Kumar equation of state," Physica B, vol. 292, no. 1-2, pp. 173-175, 2000. 

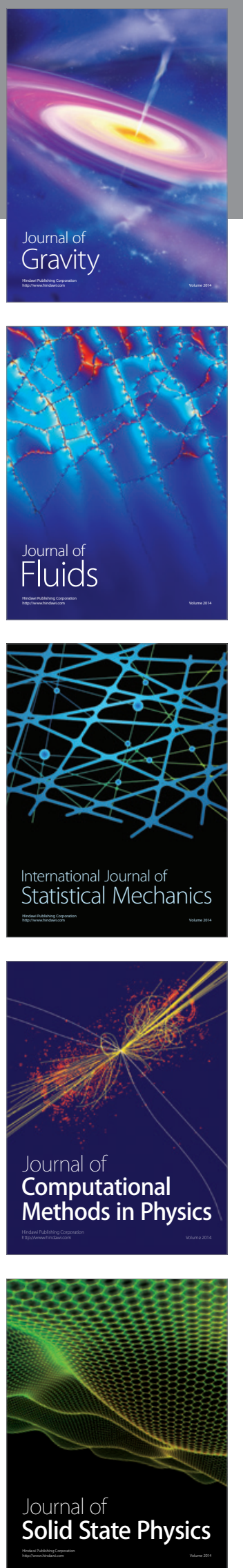

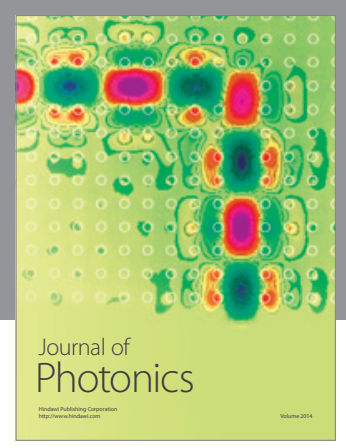

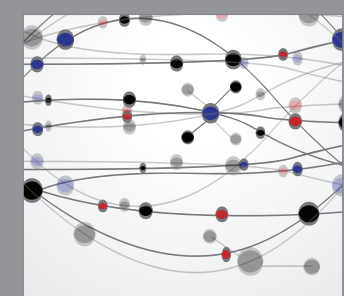

The Scientific World Journal
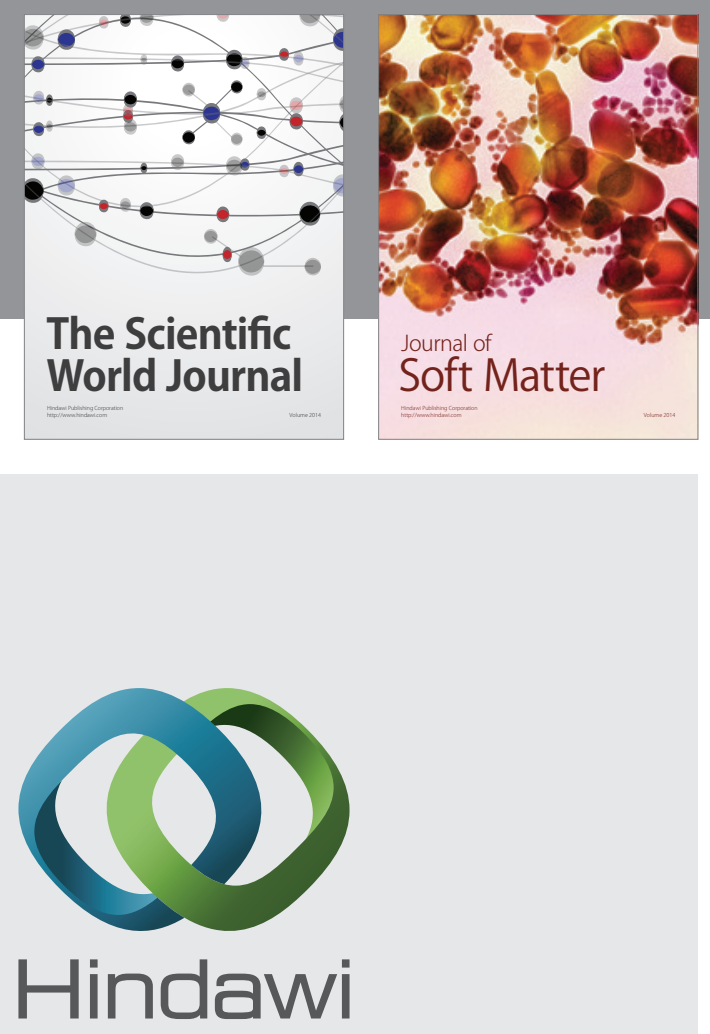

Submit your manuscripts at

http://www.hindawi.com
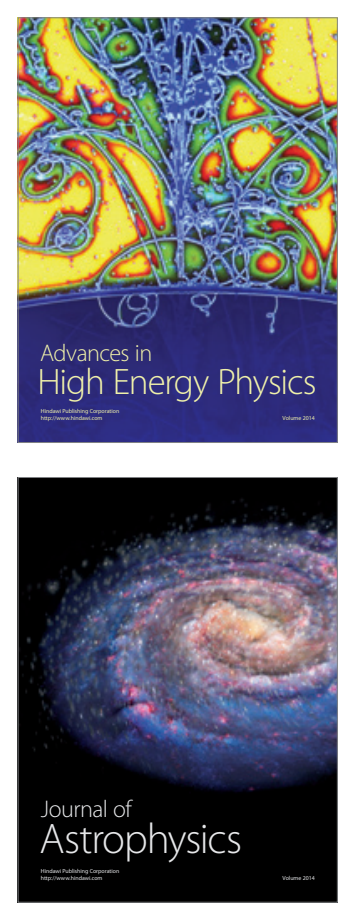
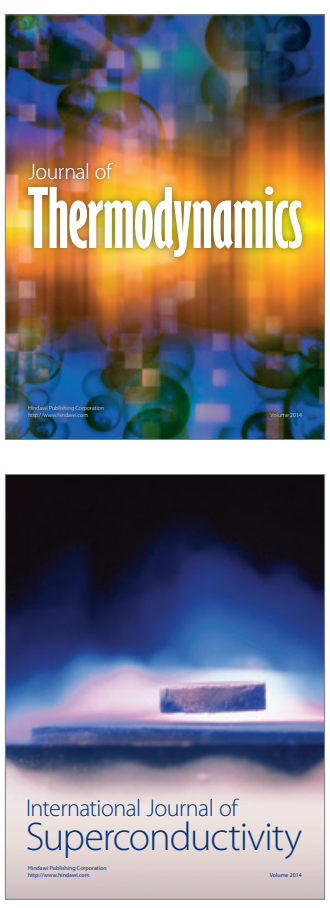
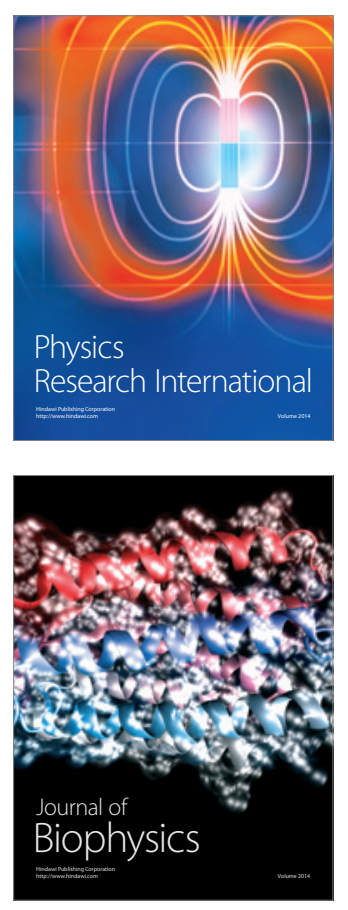
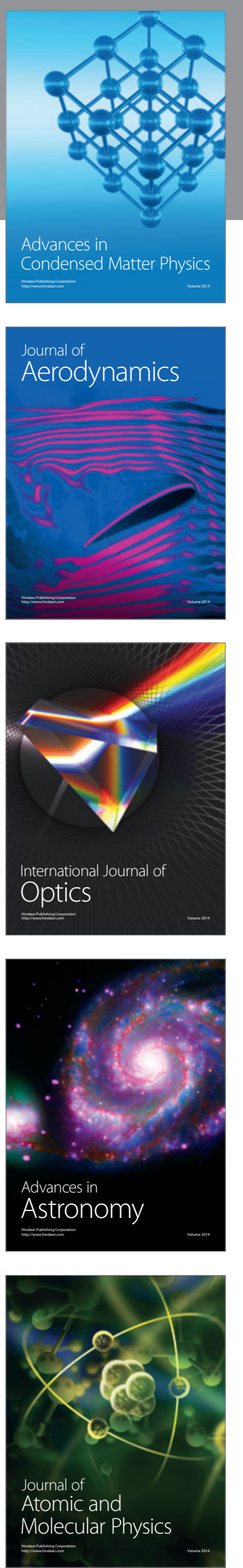